\title{
Sharing Culture and Belonging Through Cross-Cultural Collaborative Painting
}

\author{
Vanessa Maree Barbay \\ Australian National University, Canberra, Australia
}

\begin{abstract}
The topic of this paper is animals in painting and the investigative process undertaken by the artist Vanessa Barbay during her practice-led Ph.D.. Her aim was to discover a way to present deceased animals that retained their agency as individuals by challenging the objectifying nature of representation. The foundation of this method was the collaboration between artist and dead animal subjects through harnessing the natural decomposition of the subject in order to generate their image. A related stream of Barbay's research was learning about the art and culture of Kunwinjku speaking artists living in Kunbarlanja Western Arnhem Land where artists have painted images of animals on rock shelters and on bark from ancient through to contemporary times. The significance of their form of animal representation is a mythopoeic relationship between locally found pigments and animal bodies. Paintings are considered as collaboration between matter, subject, and artist, which Barbay extends in her current work centred on collaborative painting involving more than one artist.
\end{abstract}

Keywords: painting, animals, pigments, Kunwinjku, shroud, decomposition

\section{Introduction}

When working as an artist in communities the author has found a place for her practice within intercultural social zones where her role is to communicate cultural exchange using materials, creative actions and the resulting images or forms rather than words. This often silent, collaborative or demonstrative labour was an effective way to facilitate connections between individuals with different cultural backgrounds as well as between generations. Public painting practice, either portable or site specific, can bring disparate members of a community together. Of significance to these exchanges was the author's focus on animals as subjects. Animals have an important role in multicultural societies as signs that can convey cultural diversity.

\section{Animals in Painting}

The author explored the animal body as a site for enculturation firstly through experiments creating animal "images" by harnessing the decomposition of animal bodies. The relational nature of what the author called the "shroud" project concerned our shared animal body and its disintegration after death and the collaborative form of the shroud image for which the author is facilitator as the subject produces the representation. In a distant paddock under a eucalyptus tree on a farm, Adam Bell and the author set up an installation for the purpose of placing dead creatures on canvas fixed to a sprung bed base (and later a trampoline) to decompose over several months in order to produce a print or shroud-like impression of the body (Barbay, 2011). The author adopted

Vanessa Maree Barbay, Ph.D., Painting Workshop, School of Art, Australian National University. 
the term "shroud" to describe the process, as the canvas becomes a cloth evidencing physical contact with a corpse. The author acknowledged the alternative terms "trace" or "skin" are also applicable. The shroud component of the author's research enabled her to "collaborate" with the dead animal subject, allowing an interrogation of the subject-object relationship within representation. It also facilitated a deeper personal investigation revealing the source of her compulsion to represent animals.

Secondly, the author conducted research in Western Arnhem Land in the Kunwinjku speaking community of Kunbarlanja where extensive rock art "galleries" evidence the representation of animals by Aboriginal painters from ancient through to contemporary times alongside a thriving portable bark painting industry. Both areas of research have led to the author's current interdisciplinary project that uses collaborative painting practice as a research tool within visual anthropology. When the author lived and worked in Kunbarlanja briefly in 2009 and for three months in 2010, she observed anthropologists and archaeologists consulting with Kunwinjku using the tried and tested ethnographic research methodologies particular to their disciplines. As an artist, the author was unsure about formal interviews and relied upon conversations in regular social contexts precipitated by artistic or hunting activities, as they were related to her focus on animals and matter. For example, the author would offer Kunwinjku artist's paper, a brush and ochre she had brought with her from home, which the author ground into paint indicating they could paint together. The results ranged from paintings made in front of the author while she was given a verbal cultural education; paintings made alongside the author while she also painted prompting her to be observed and questioned by Kunwinjku painters about her abilities and style; to workshop-based painting where the author was taught to paint like Kunwinjku through mimicry.

The cross-cultural public context in which works were produced at Injalak Arts and Crafts in Kunbarlanja reflected the positive economic and social role arts practice had in the community. However, it was also obvious to Kunwinjku that most interactions between Balanda or non-Kunwinjku and Kunwinjku were mediated through the photographic "gaze". This created an atmosphere of separation or detachment and made artists self-conscious. This prompted the author to give Kunwinjku artists her camera so they could take photos of her instead. The author's role at Injalak was describing, selling, packing, and sending works made at Injalak (or at the home of artists living in Kunbarlanja and surrounding outstations) to tourists, collectors, and galleries. The author also took artists out on country to collect art materials such as fibre and dye plants for weaving; bark, reeds, and ochre for paintings; and wood for making mako or didgeridoos, traditional weapons, and carvings. The collaborative effort involved in the collecting part of the art process, while hard work, played a significant role in caring for country and the cultural education of children. Usually collecting was a gendered activity with women and children focused on materials for weaving and men on carving and painting materials. However, significant excursions to country by traditional owners involved extended family groups camping for periods of time to collect art materials while hunting, fishing and visiting relatives.

\section{Cross-Cultural Learning About Pigments}

One particularly special journey the author helped facilitate with members of the Warddjak clan was to country not visited by traditional owners either at all or for over 30 years. The area was called Maburrinj located on the Gumadeer River in Western Arnhem Land and there was no road or map to guide them. Members of the expedition relied on memories and perception to track a path through bush, swamps, creeks, and rocky plateaus where annabarru or buffalo lived in family groups. Although they did stray off course and 
the troopy became bogged in a creek, the journey was successful as they found the sacred white ochre or delek site named Madjarlngalkum and an additional yellow ochre or karlba site. There was also a purple pigment site near an emu dreaming stone arrangement, which they did not visit, although they collected a red pigment called gunnodjbe from an airstrip at a neighbouring abandoned outstation called Kudjekbinj. These places were oases in the hot dry season protected by their inaccessibility. Unfortunately uranium-mining exploration will begin in the mid-2014, which will involve the construction of a road making the need for protection of these valuable sacred sites imminent.

The author's subsequent but rather limited research in the field of Anthropological theory had revealed her intuitive methodology was similar to what is termed:

The observation of participation [where, as Barbara Tedlock explains], ethnographers both experience and observe their own and others' co-participation within the ethnographic encounter [leading to] both the Self and Other [being] presented together within a single narrative ethnography, focused on the character and process of the ethnographic dialogue. (Tedlock, 1991, p. 69)

Tedlock (1991) notes the conflict within the “oxymoron 'participant observation' [and references Benjamin Paul stating] Participation implies emotional involvement; observation requires detachment. It is a strain to try and sympathise with others and at the same time strive for scientific objectivity” (p. 69). On the observer/participant scale presented by Paul Atkinson and Martyn Hammersley the author's experience reflected a "complete participant” (Atkinson \& Hammersley, 1994, p. 248) approach due in part to a lack of concern for scientific objectivity and the absence of what Bob Scholte describes as "the ethnological tradition 'in the head' of the ethnographer" (Scholte, 1969, p. 438). Reflexive anthropology can also be considered a practice-led form of research, impressing on the author the need to assert her matter-based perspective as a painter and painting practice as a research tool.

While research questions were in her head and did manifest several opportunities for exploration, the author found herself more involved with the relationships she was building and navigating the socio-cultural environment in Kunbarlanja. The author became aware of being studied by Kunwinjku who noted she was different to most other Balanda or outsiders, due to her willingness to learn language and accommodate cultural and individual responsibilities expected when abiding by the kinship system. At times this required putting aside the moral philosophy prevalent in the culture the author was schooled in, which was notably Catholic. The author learnt a lot about the value of collaboration from living and working amongst Kunwinjku, particularly the importance of networking in order to enlarge familial connections to increase resources in a social system based on sharing or exchange rather than individual gain. This approach to life encompassed art making where work was usually made in gendered social groups or extended family groups so children participated. The art advisor or manager of the art centre is an important part of this collaborative network today contributing to the work's creation. Although there were "star artists" whose art was valued for its individuality, collaboration often occurred either for educational purposes or economic efficiency, and while one artist may submit a work on buying day as their own, a collaborative effort forms the foundation of many works, from their material realization to their meaning as art based on an ancestral socio-cultural connectivity that includes non-human animals. It is this shared experience in relation to living in a particular place for generations among other species that the author also focuses on in her own work. This interspecies connectivity is expressed through a consubstantial perception of matter, which implicates the art materials in the meaning of a work. 
To demonstrate briefly, pigments the author collected with members of the Warddjak clan were described as bodily substances left by animal or human Ancestral beings. Delek, the white chalk they extracted from the mud beside a bend in the Gumadeer River, is known as the sacred faeces of Ngalyod the rainbow serpent. It was ceremoniously consumed and smeared over the face, hair, and body. Later the author noted the visual similarity between snake excrement and the white delek embedded in the brown mud. Materially delek dries and crumbles like faeces being the first pigment to deteriorate in rock paintings. The rich yellow sticky mud karlba is known as the fat of an Ancestral emu, and again the visual and material similarity is clear. The red kunnodjbe is known as the menstrual blood of Ancestral women and is a staining penetrating pigment lasting in rock art for thousands of years.

\section{The Social Agency of Art Objects}

A focus on materials as significant indicators of the social functioning or agency of an art object forms the foundation of the author's research and reveals that art is a collaborative phenomenon. Artists work within specific socio-cultural environments offering particular materials within economic systems that support and/or impact on all living and non-living entities that inform the conceptual and material substance of art objects. While Modern Art's legacy is the individual genius, an artist is not entirely autonomous, and their role as "outsider" or anomaly is more revealing when they are viewed as indicators or representatives of particular cultural networks fed by the economic and social interests of many. The author's perception of the artist and their work as social agents is based on practice-led research, which is by nature self-reflexive and participatory. The author refers to Alfred Gell's anthropological theory of art extrapolated in Art and Agency (1998), which is defined as "social relations in the vicinity of objects mediating social agency" (p. 7). By focusing on the exchange between human and non-human animals, the author's research is inclusive and seeks to dissipate distinctions between self and other. It was the "shroud" project, in which the author collaborated with deceased animals, that was most revealing of creative process as a shared exchange between entities that constitute matter found within a specific environment.

From the moment the author encountered the body of an animal by the road or on the farm where the project installation was located, collaboration was occurring. The network of exchanges between human and non-human animals enabling the art objects to manifest reveals a multiple authorship. Adam Bell helped the author collect, store, transport, and install the animal bodies; Steven Holland and Tony facilitated the project by allowing it to occur on their property. The author's Ph.D. supervisors, Nigel Lendon and Vivienne Binns, contributed advice and encouragement throughout the project, and her inward exegetical journey revealed the source of her compulsion to work with deceased animals was her father, whose blend of artistic and zoological focus manifest in his practice of taxidermy. Taxidermy is a chemical process with an unnatural logic, which the shroud deconstructs from the inside out. Taxidermy mends the borders of a body already beyond itself, while the shroud image captures this "beyond self". The image produced by the decomposing dead presents matter ordered according to the inside as it exits the convulsing border of the subject. The author's father taught her the practice of taxidermy, and his arrangement of dead animals for display were intended to reanimate them, while simultaneously inhibiting the corporeal afterlife of the body through maggot, beetle, and moth “infestation”. There was a sad irony behind the author's father's taxidermy practice, as a refugee from the soviet occupation of Hungary he had left behind an apprenticeship as a zookeeper to become "a man who is the attendant of corpses” (Lincoln, 1991, p. 110). 
Throughout the shroud process the author stressed the importance of agency attributed to the animal subject through the art object, which is strengthened, the author believes, by the consubstantial relationship between the animal and the shroud. In semiotic terms, this relationship could be described as indexical for the collection of material evidence from the animal body "fallen apart" in death constituted by the shroud as signifier, is an index of the animal subject signified. The animal body is also the author's body as a human animal. Like Haraway (2008), "I love that when 'I' die, all these benign and dangerous symbionts will take over and use whatever is left of 'my' body, if only for a while, since 'we' are necessary to one another in real time” (p. 4). Enabling the inexorable unfolding of the body to leave its own trace captures an image that used and is the body it sought to represent, "a subject-and object-shaping dance of encounters" (p. 4) as Haraway (2008) described. The notion of consubstantiality and its foundational role in religious objects and ritual was the most significant discovery of the author's Ph.D. research alongside the collaborative nature of creative practice.

\section{The Power of Collaboration and Matter as Social Agents}

In the author's current collaborative cross-disciplinary project supported by ANU, consubstantiality gains a specific function as not just the link between species but between cultures through religion. Endeavouring to find synergies between Catholic and Koori cosmology, the author's collaborator Theresa Ardler and the author are working toward the creation of art objects whose agency is reparative strengthening the spiritual health and identity of ourselves and our familial communities within a shared environment. Ardler is a Koori woman from Yuin and Eora heritage, and the author has European heritage. They share the experience of growing up in the same Yuin coastal environment guided by similar Catholic and Koori spiritual education. Ardler's painting practice employs acrylics to create vibrant combinations of iconic figures and dots in symmetrical designs. She has applied the designs to both Koori objects such as boomerangs, hollow logs and rocks, and Catholic objects such as crosses, candleholders, and the robes worn by priests (Ardler, 2014, p. 10). When she came to the author's current studio space in the author's childhood home the author showed Ardler her father's taxidermy display, which she remembered seeing as a teenager, and some of the shroud paintings which they decided to work into. The author chose an echidna and mixed up the red, yellow, and white ochre the author had collected in Arnhem Land and some charcoal. The author demonstrated her use of wattle gum, a traditional binder rather than polyvinyl acetate. She proceeded to paint yellow dots with the author around the perimeter of the echidna's body stain, and the author explained the yellow indicated how fatty the body was, making echidna tasty bush tucker. Ardler decided to create alternating waves of red and black radiating out from the fatty halo, explaining the echidna was walking across country that changed from sand to dirt like their coastal home.

Ardler noted the inconsistency of the ochre in contrast to the plastic paint to which she was accustomed. Yet she has access to the ochre pits at her home in Wreck Bay and continually educates the author about local Koori creation stories, the local Dharawal language and initiation traditions. The author would like their proposed works to include ochre and bush dyeing using local plants as she was taught in Kunbarlanja. The author has the old copper used by her maternal grandmother in which to boil the canvas with plant dyes. In Kunbarlanja, the author's kinship karrang or mother and her rdarda or younger sisters taught her dyeing techniques. The process of collecting and boiling mandjurndom a yellow root and wirdilwirdil a red bulb to dye kungobahn or pandanas was a regular activity at Injalak that the author intends to emulate using canvas with Ardler for the project. 
In 2009, the author had produced ochre paintings on canvas dyed in Kunbarlanja, and feels the agency is attributable to the plants and minerals producing the colours, their origins geographically and culturally as art materials. The canvas, rabbit skin glue size shining on the surface, and square format of the stretcher frame also contribute to the social agency of the work within a European artistic tradition and context. From 2008, the author has been including bitumen as a material deliberately as an indicator of urbanisation and the resulting road kill, while early this year the deliberate inclusion of oil painting to represent the post-decomposition image of shroud producing subjects directly references European natural history painting. In 2012, the author produced a cross-cultural work that began as a shroud created by a chough and starling to which the author added ochres and oils blending Kunwinjku and Christian iconography. Catholicism was also evoked in 2011 when the author collaborated with spring lambs that had died on the farm and became for her symbols of the Lamb of God in Mass, consubstantial with the Son of God, in an offering of bread and wine consumed for renewal and expressed as the forgiveness of sins. Further meaning can be attributable through materials to time and place, and Theresa indicated the importance of seasons in Koori and Catholic ritual. The author spoke about the seasonal availability of plants for dyeing and animals for hunting, or in this case, their symbolic or indexical presence in works through both painted representations and the shroud process. Catholic and Koori iconography may be incorporated but the focus is on the physical relation between materials and their meaning in order to infuse the resulting art objects with a consubstantial power strengthening their agency as sacred entities in and of themselves.

\section{Conclusion}

By considering the art object (in this case a painting), as collaborative or a process linking artist(s), subject(s) and matter, agency is then shared but ultimately resides in the art object. Once taken out of its cultural or material context, the art object must operate as a social agent in and of itself without necessarily consideration for the artist or the subject. Power ultimately resides in the matter of which the art object consists and how that matter is combined into a sign. If the sign has been generated through an indexical process (whereby the sign and its referent consist of the same substance) then the subject's agency is maintained. Representation usually, however, relies on a symbolic or iconic process (whereby the sign and its referent have an arbitrary or visual relationship), which indicates the agency of the artist. The author's aim in this project was to allow the subject to retain agency by ensuring the art object retains a physical element of the subject at the level of matter.

\section{References}

Ardler, T. (2013). Vanessa Barbay. In J. Kochel (Ed.), VCCVAFS: Vice-chancellor’s college visiting artists fellowship scheme (p. 10). Canberra: Australian National University.

Atkinson, P., \& Hammersley, M. (1994). Ethnography and participant observation. In N. K. Denzin, \& Y. S. Lincoln (Eds.), Handbook of qualitative research (pp. 248-261). Thousand Oaks, London, New Delhi: Sage Publications.

Barbay, V. (2011). New shroud set. Canberra: laomedia. Retrieved from http://laomedia.com/blog/?m=201101

Gell, A. (1998). Art and agency: An anthropological theory. Oxford: Clarendon Press.

Haraway, D. J. (2008). When species meet. C. Wolfe, (Ed.). Minneapolis, London: University of Minnesota Press.

Lincoln, B. (1991). Death, war and sacrifice: Studies in ideology and practice. Chicago, London: University of Chicago Press.

Scholte, B. (1969). Toward a reflexive and critical anthropology. In D. Hymes (Ed.), Reinventing anthropology (pp. 430-457). New York: Pantheon Books.

Tedlock, B. (1991). From participant observation to the observation of participation: The emergence of narrative ethnography. Journal of Anthropological Research, 47(1), 69. 